Article

\title{
Effects of Interval Jump Rope Exercise Combined with Dark Chocolate Supplementation on Inflammatory Adipokine, Cytokine Concentrations, and Body Composition in Obese Adolescent Boys
}

\author{
Mozhgan Eskandari ${ }^{1}$, Babak Hooshmand Moghadam 2,3® ${ }^{\circledR}$, Reza Bagheri ${ }^{4, *}$, \\ Damoon Ashtary-Larky ${ }^{5}$, Elham Eskandari ${ }^{6}$, Michael Nordvall ${ }^{7}$ (D) Frédéric Dutheil ${ }^{8}$ and \\ Alexei Wong ${ }^{7, *}$ \\ 1 Department of Exercise Physiology, University of Birjand, Birjand 9717434765, Iran; \\ Mozhgan.eskandari@birjand.ac.ir \\ 2 Department of Exercise Physiology, University of Tehran, Tehran 1961733114, Iran; \\ b.hooshmand.m@gmail.com \\ 3 Department of Exercise Physiology, Ferdowsi University of Mashhad, Mashhad 9177948974, Iran \\ 4 Department of Exercise Physiology, University of Isfahan, Isfahan 81746-73441, Iran \\ 5 Nutrition and Metabolic Diseases Research Center, Ahvaz Jundishapur University of Medical Sciences, \\ Ahvaz 61357-15794, Iran; damoon_ashtary@yahoo.com \\ 6 Qaen school of Nursing and Midwifery, Birjand University of Medical Sciences, Birjand 9717853577, Iran; \\ elhamskandari70@gmail.com \\ 7 Department of Health and Human Performance, Marymount University, Arlington, VA 22207, USA; \\ michael.nordvall@marymount.edu \\ 8 Université Clermont Auvergne, CNRS, LaPSCo, Physiological and Psychosocial Stress, CHU \\ Clermont-Ferrand, University Hospital of Clermont-Ferrand, Preventive and Occupational Medicine, \\ Witty Fit, F-63000 Clermont-Ferrand, France; fred_dutheil@yahoo.fr \\ * Correspondence: will.fivb@yahoo.com (R.B.); awong@marymount.edu (A.W.); \\ Tel.: +98-9379092551 (R.B.); +1-7039087609 (A.W.)
}

Received: 13 August 2020; Accepted: 28 September 2020; Published: 30 September 2020

check for updates

\begin{abstract}
We examined the effects of six weeks of dark chocolate supplementation combined with interval jump rope exercise (JRE) on inflammatory cytokines, adipokines, and body composition in obese adolescent boys. Forty-eight obese adolescent boys (age $=15.4 \pm 1.1$ years and body mass index $=32.2 \pm 2.4 \mathrm{~kg} / \mathrm{m}^{2}$ ) were randomly assigned into one of four groups: JRE + white chocolate (JW; $n=13)$, JRE + dark chocolate supplementation (JD; $n=13)$, dark chocolate supplementation (DS; $n=12)$, or control (C; $n=12$ ). Participants in JW and JD groups performed JRE for three times per week for six weeks. Participants in the DS and JD groups consumed $30 \mathrm{~g}$ of dark chocolate containing $83 \%$ of cocoa. Body composition, pro-inflammatory cytokines ((hs-CRP, TNF- $\alpha$, IL-6), adipokines (leptin, resistin, RBP-4, chemerin, MCP-1), and anti-inflammatory adipokines (irisin, adiponectin)) were evaluated prior to and after the intervention trials. All three intervention trials significantly $(p<0.05)$ decreased body mass, waist-hip ratio, fat mass, hs-CRP, TNF- $\alpha$, IL-6, leptin, resistin, RBP-4, and MCP-1, and increased irisin and adiponectin concentrations. The improvements in these parameters were greater in the JD group, and additionally, chemerin concentrations decreased only in the JD group. JD enhanced adiponectin concentrations and decreased IL- 6 concentrations compared to C. Moreover, JD significantly reduced chemerin concentrations, an effect not observed in any of the other interventions. We demonstrated that dark chocolate supplementation potentiated JRE-induced decreases in body mass, WHR, FM, hs-CRP, TNF- $\alpha$, IL-6, leptin, resistin, RBP-4, and MCP-1, chemerin as well as increases irisin and adiponectin concentrations in obese adolescent boys. Therefore, JRE combined with dark chocolate supplementation could be a beneficial in reducing obesity-induced inflammation in adolescent boys.
\end{abstract}


Keywords: fat mass; dark chocolate; obesity; body composition; inflammation

\section{Introduction}

It is well established that obesity in youth populations causes alterations in the balance between proand anti-inflammatory cytokine and adipokine secretions, resulting in an inflammatory response [1,2]. Indeed, chronic inflammation due to obesity in adolescents and children is a well-known chief risk factor for numerous clinical diseases observed in later adulthood, such as type 2 diabetes mellitus and cardiovascular disease [3].

Numerous physical activity strategies, including jump rope exercise (JRE) [4], have been proposed as a way to combat inflammation and improve health in obese populations [5,6]. For instance, $40 \mathrm{~min}$ of daily JRE for six weeks improved insulin sensitivity as well as triglyceride and adiponectin concentrations in obese adolescents [4]. JRE modality requires minimal and inexpensive equipment as well as limited space, which may promote improved exercise adherence in various populations. Additionally, JRE has been proven to reduce inflammatory cytokine and adipokine concentrations in adolescent cohorts, leading to improvements in various body composition and cardiovascular health indices $[4,7,8]$.

Dietary supplements are also receiving substantial interest as a strategy to combat inflammatory-related risk factors in obese populations. A growing body of evidence indicates that cocoa displays beneficial antioxidant and anti-inflammatory properties due to its high flavonoid content including epicatechin, catechin, and proanthocyanidins [9,10]. Indeed, the consumption of food containing cocoa, such as dark chocolate, has been linked to improved health-related markers. For instance, eight weeks of $84 \%$ dark chocolate supplementation along with therapeutic lifestyle changes guidelines reduced inflammatory markers (high-sensitivity C-reactive protein (hs-CRP), tumor necrosis factor-alpha (TNF- $\alpha$ ), and interleukin-6 (IL-6)) in type 2 diabetic patients [11]. Moreover, eight weeks of dark chocolate supplementation (containing $450 \mathrm{mg}$ polyphenols) decreased hs-CRP concentrations, blood triglyceride, and apo-lipoproteins A-1 and B in diabetic patients [12]. A recent review article indicated that cocoa-rich food intake may lessen inflammation by reducing monocytes and neutrophils activation [13]. Prior research indicates that combining exercise with another anti-inflammatory treatment may offer additive effects of improving circulating concentrations of inflammatory markers [14].

While the anti-inflammatory effects of exercise in obese adolescents are well established [15-18]; the impact of the combination of JRE and dark chocolate supplementation on inflammatory status in this population has yet to be investigated. Moreover, the effects of chronic dark chocolate consumption on inflammatory markers in obese adolescent cohorts are currently unknown. Therefore, we aimed at investigating the effects of dark chocolate supplementation alone and in combination with JRE on select markers of inflammation (hs-CRP, TNF- $\alpha$, IL-6, Leptin, Resistin, Monocyte chemoattractant protein-1 (MCP-1), Adiponectin, Chemerin, Irisin, and Retinol-binding protein-4 (RBP-4)). We conducted a randomized, placebo-controlled study to assess the aforementioned effects in obese adolescent boys.

\section{Materials and Methods}

\subsection{Participants}

Forty-eight obese adolescent boys (age $=15.4 \pm 1.1$ years and height $=165.9 \pm 4.9 \mathrm{~cm}$ ) participated in the current study. All participants were obese (body mass index (BMI) equal to or greater than the 95th percentile for age and sex), according to guidelines for youth populations [19]. The inclusion criteria for the study were as follows: ages 13 to 17 years, obesity, weight loss of no more than two kilograms over the last six months, sedentary, participating in less than $1 \mathrm{~h}$ of physical activity per week over the last year, and no recognized illnesses, such as cardiovascular disease, diabetes, or similar. 
All participants were reportedly non-smoking and not consuming alcoholic or caffeine-containing beverages at the time of data collection. Dietary supplementation and drugs affecting muscle mass and adipose tissue metabolism, including amino acids, beta-blockers, beta-agonists, calcium channel blockers, and corticosteroids, were also grounds for exclusion. Information about disease and health status as well as all remaining exclusion criteria was obtained via PAR-Q and appraised by a physician. Participants and their parents provided informed consent before study enrollment. The Institute of Physical Education and Sports Sciences (Tehran, Iran) Human Subject Committee approved the study protocol, which was performed in Mashhad, Iran, and all experimentation was carried out in accordance with the Declaration of Helsinki. The study was registered in the Iranian Registry of Clinical Trials (IRCT20151025024699N5).

\subsection{Study Design}

This study was conducted between January and March of 2019. A schematic of the study design is depicted in Figure 1. Before pre-test measurements, our participants were completely acquainted with all measurements. Participants were randomly assigned into one of four groups as follows: JRE + white chocolate supplementation (JW; $n=13$ ), JRE + dark chocolate supplementation (JD; $n=13$ ), dark chocolate supplementation (DS; $n=12)$, or control (C; $n=12)$. The randomization assignment was stratified by a digital tool (available at www.randomizer.org). Measurements were collected on two occasions, at baseline and again at 6 weeks post interventions (minimum 48-72 $\mathrm{h}$ after the last JRE session). All assessments were performed at the same time of day (within $1 \mathrm{~h}$ ) and under the same environmental conditions $\left(\sim 20^{\circ} \mathrm{C}\right.$ and $\sim 55 \%$ humidity). Participants were asked to avoid modifying their normal lifestyle and dietary habits during the study.

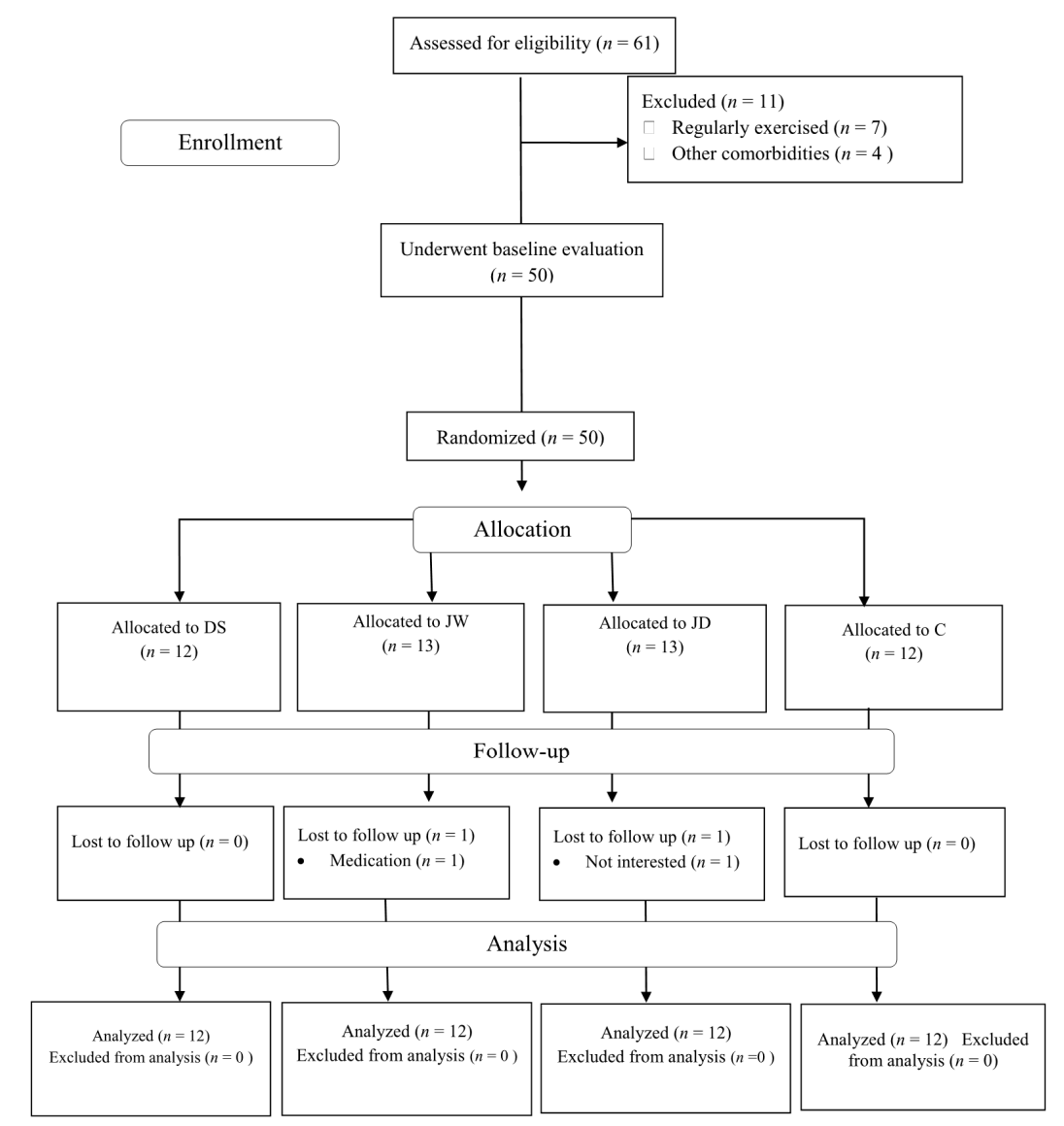

Figure 1. Participants Flow Diagram. Abbreviations: JW, jump rope exercise + white chocolate; JD, jump rope exercise + dark chocolate supplementation; DS, dark chocolate supplementation; $\mathrm{C}$, control. 


\subsection{Anthropometry and Body Composition}

Participants were instructed to fast for $12 \mathrm{~h}$ (overnight fast, with at least $8 \mathrm{~h}$ of sleep) and abstain from physical activity and alcohol consumption for $48 \mathrm{~h}$ prior to anthropometric and body composition data collection. Upon arriving at the laboratory, they were asked to void completely within $30 \mathrm{~min}$ prior to data collection. We measured participants' body mass with a digital scale (Lumbar, Hong Kong, China) to the nearest $0.1 \mathrm{~kg}$. The participant's height was measured with a stadiometer (Race Industrialization, Shanghai, China) to the nearest $0.1 \mathrm{~cm}$. A multi-frequency bioelectrical impedance analyzer (Jawon Medical X-Contact 356, Seoul, Korea) evaluated body mass index (BMI) and provided estimates of fat mass (FM) and waist-hip ratio (WHR) as previously described [20].

\subsection{Blood Sampling and Laboratory Analysis}

Fasting blood samples $(20 \mathrm{~mL})$ were taken from the median cubital vein utilizing standard techniques following 12-h overnight fasting. Blood samples were taken at baseline and $48 \mathrm{~h}$ after the final JRE session. Following blood sampling, samples were centrifuged at $3000 \mathrm{rpm}$ for $10 \mathrm{~min}$, and the serum was stored at $-80{ }^{\circ} \mathrm{C}$ for future analysis of adiponectin (sensitivity: $1.1 \mathrm{ng} / \mathrm{mL}$ ), leptin (sensitivity: $0.06 \mathrm{ng} / \mathrm{mL}$ ), resistin (sensitivity: $0.07 \mathrm{ng} / \mathrm{mL}$ ), Monocyte Chemoattractant Protein-1 (MCP-1; sensitivity: 30.1 pg/mL), Interleukin-6 (IL-6; sensitivity: 2.4 pg/mL), Tumor Necrosis Factor- $\alpha$ (TNF- $\alpha$; sensitivity: $1.9 \mathrm{pg} / \mathrm{mL}$ ), hs-CRP (sensitivity: $0.1 \mathrm{ng} / \mathrm{mL}$ ), chemerin (sensitivity: $7.8 \mathrm{ng} / \mathrm{mL}$ ), Irisin (sensitivity: $0.7 \mathrm{ng} / \mathrm{mL}$ ), and Retinol-binding protein-4 (RBP-4; sensitivity: $3.9 \mathrm{ng} / \mathrm{mL}$ ). Intra and inter-assay coefficient variations for all markers were less than $8 \%$ and $10 \%$, respectively (CUSABIO, Houston, TX, USA).

\subsection{JRE Protocol}

JRE was performed five times per week, $40 \mathrm{~min} /$ day for 6 weeks. Total exercise duration per session was $40 \mathrm{~min}$ and entailed $30 \mathrm{~min}$ of JRE as well as warm-up and cool down periods consisting of $5 \mathrm{~min}$ of stretching. JRE was performed at a rate of 60 jumps/min for the 1 st three weeks and progressed to 90 jumps/min over the remaining 3 weeks. Individual bouts of JRE per exercise session as well progressed over the 6-week study period and were followed by brief rest periods. JRE cadence was established through the utilization of a metronome. All JRE sessions were monitored by personal trainers who verified adherence to the training protocol. The selected JRE protocol is similar to prior research in obese populations [4]. Table 1 represents the JRE protocol.

Table 1. Jump rope exercise protocol for the JW and JD groups.

\begin{tabular}{|c|c|c|c|c|}
\hline \multirow{2}{*}{ Week } & \multirow{2}{*}{$\begin{array}{l}\text { Intensity } \\
\text { (Jump/min) }\end{array}$} & \multicolumn{3}{|c|}{ Training Duration } \\
\hline & & Warm-Up (5 min) & Exercise $(30 \mathrm{~min})$ & Cool-Down $(5 \mathrm{~min})$ \\
\hline 1 & 60 & \multirow{6}{*}{ Stretching } & $\begin{array}{l}20 \text { sets of } 1 \text { min of exercise, followed by } \\
30 \text { s of rest }\end{array}$ & \multirow{6}{*}{ Stretching } \\
\hline 2 & 60 & & $\begin{array}{c}15 \text { sets of } 1.5 \text { min of exercise, followed } \\
\text { by } 30 \text { s of rest }\end{array}$ & \\
\hline 3 & 60 & & $\begin{array}{l}12 \text { sets of } 2 \text { min of exercise, followed by } \\
30 \text { s of rest }\end{array}$ & \\
\hline 4 & 90 & & $\begin{array}{c}10 \text { sets of } 2.5 \text { min of exercise, followed } \\
\text { by } 30 \text { s of rest }\end{array}$ & \\
\hline 5 & 90 & & $\begin{array}{c}9 \text { sets of } 3 \text { min of exercise, followed by } \\
30 \text { s of rest }\end{array}$ & \\
\hline 6 & 90 & & $\begin{array}{c}7 \text { sets of } 4 \text { min of exercise, followed by } \\
30 \text { s of rest }\end{array}$ & \\
\hline
\end{tabular}

$\mathrm{JW}$, jump rope exercise + white chocolate supplementation; JD, jump rope exercise + dark chocolate supplementation. 


\subsection{Dark Chocolate Supplementation}

Participants in both JD and DS groups consumed $30 \mathrm{~g}$ per day of dark chocolate containing $83 \%$ of cocoa (Farmand Gallardo 83 Percent Dark Chocolate) for six weeks. To limit the psychological impact (placebo effect) of not receiving the dark chocolate dietary supplement, participants in the JW group consumed white chocolate of the same shape and packaging (coated with aluminum foil) and devoid of cocoa [21]. Participants received their respective supplementation daily as a midafternoon snack [22]. The ingredients of $30 \mathrm{~g}$ of dark and white (placebo) chocolate are shown in Table 2 . The dose and timing of the supplementation were similar to a previous investigation reporting the anti-inflammatory effects of dark chocolate [23]. Participants were reminded weekly by phone call and WhatsApp software to consume the dark chocolate supplement in order to maximize study compliance.

Table 2. Energy and nutrient composition of both dark and white chocolate supplements.

\begin{tabular}{ccc}
\hline Content Per Dose & Dark Chocolate & White Chocolate \\
\hline Energy $(\mathrm{kcal})$ & 184.5 & 168.8 \\
\hline Total fat $(\mathrm{g})$ & 14.6 & 10.7 \\
\hline Carbohydrate $(\mathrm{g})$ & 5.1 & 14.7 \\
\hline Protein $(\mathrm{g})$ & 8.2 & 3.4 \\
\hline Cacao polyphenol $(\mathrm{mg})$ & 2650 & 0 \\
\hline Epicatechin $(\mathrm{mg})$ & 160 & 0 \\
\hline Caffeine $(\mathrm{mg})$ & 130 & 0 \\
\hline Theobromine $(\mathrm{mg})$ & 960 & 0 \\
\hline Cocoa $(\%)$ & 83 & \\
\hline
\end{tabular}

Abbreviations: kcal, kilocalorie; g, gram; mg, milligram.

\subsection{Nutrient Intake and Dietary Analysis}

Owing to the significant role of nutritional timing surrounding training sessions, dietary intake in the $\mathrm{h}$ near (before and after) the JRE sessions were controlled [24]. Our participants consumed a banana that provided $0.30-0.35 \mathrm{~g}$ of carbohydrate per kilogram of body mass, as a pre-training snack $1 \mathrm{~h}$ before the training session. Moreover, dinner was consumed 1.5-2 $\mathrm{h}$ after each exercise session and was standardized to contain $1.7 \mathrm{~g} / \mathrm{kg}$ of body mass of carbohydrate, $0.3 \mathrm{~g} / \mathrm{kg}$ of body mass of protein, $0.4 \mathrm{~g} / \mathrm{kg}$ of body mass of fat [25]. These values were according to recommendations by the Academy of Nutrition and Dietetics, Dietitians of Canada, and the American College of Sports Medicine for macronutrient distribution (55-65\% of total calories from carbohydrates, $<35 \%$ of total calories from fats and 10-15\% of total calories from protein). Beyond this peri-training nutrient intake standardization, the participants were asked to avoid altering their dietary habits during the study. Our participants were asked to submit 3-day ( 2 weekdays and 1 weekend) food records at pre-intervention and near the end of the assigned intervention. Each food item was individually entered into the Diet Analysis Plus version 10 program (Cengage, Boston, MA, USA) and total energy consumption as well as the nutrient breakdown of proteins, fats, and carbohydrates, was assessed.

\subsection{Statistical Analysis}

We conducted a priori calculation of sample size utilizing the G*Power analysis software [26]. Our rationale for sample size was according to prior data [4,11] and estimated that 12 participants (48 total) per group would provide $80 \%$ power (two-sided $\alpha=0.05$ ) to detect $7 \%$ changes in several of our markers (adiponectin, leptin, hs-CRP, and IL-6). However, we attempted to recruit $10 \%$ extra participants (5 extra participants) to account for any potential attrition. Data normality was checked using the Shapiro-Wilk test. A one-way analysis of variance (ANOVA) was used for group comparisons 
at baseline. A two $\times$ four ANOVA with repeated measures (time (baseline vs. 6 weeks) $\times$ group $($ JW vs. JD vs.DS vs. C)) with Bonferroni-Holm adjustments was used to determine treatment differences. When a significant group-by-time interaction was presented, one-way ANOVA across change scores was used to detect between-group differences. Statistical significance was set at $p<0.05$. Cohen's $d$ effect size (ES) was calculated as post-JRE effect mean minus pre-JRE effect mean/pooled pre-JRE effect standard deviation means [27]. An ES of 0.00-0.19 was considered trivial, $0.20-0.49=$ small, $0.50-0.79$ $=$ moderate, and $\geq 0.80=$ large. All analyses were performed using SPSS (version 24.0, IBM; Chicago, IL, USA).

\section{Results}

Between January and March of 2019, we screened 61 obese adolescent boys. Of these only 50 met the criteria for baseline evaluation, and were subsequently randomized to the JW, JD, DS, or C groups. After randomization, one participant in the JW and one participant in the JD group dropped out of the study for health and unwillingness reasons. Compliance with JRE was nearly $92 \%$ for participants in both the JW and JD groups. Compliance with dark chocolate supplementation was 100\% for participants in the DS group. No adverse events were reported from dark chocolate consumption or JRE. There were no significant differences at baseline between groups for all variables. In addition, there were no significant differences over time or between groups in mean daily energy intake as well as the amount of proteins, fats, and carbohydrates consumed per day (Table 3).

Table 3. Energy and macronutrients at baseline after 6 weeks.

\begin{tabular}{|c|c|c|c|c|}
\hline Variable & Group & Baseline & Post-Intervention & $\mathbf{P}$ \\
\hline \multirow{4}{*}{ Energy $(\mathrm{kcal} / \mathrm{d})$} & JW & $1969.8 \pm 45.1$ & $1957 \pm 42.3$ & 0.384 \\
\hline & DS & $1958.7 \pm 71.2$ & $1953.1 \pm 69.7$ & 0.540 \\
\hline & JD & $1982.5 \pm 58.6$ & $1968.8 \pm 43$ & 0.428 \\
\hline & $\mathrm{C}$ & $1959.1 \pm 44.3$ & $1954 \pm 49.2$ & 0.721 \\
\hline \multirow{4}{*}{ Protein $(\mathrm{g} / \mathrm{d})$} & JW & $94.2 \pm 5.1$ & $94.3 \pm 6$ & 0.959 \\
\hline & DS & $92.5 \pm 5.6$ & $93 \pm 5.7$ & 0.702 \\
\hline & JD & $94.8 \pm 4.9$ & $94.2 \pm 5.7$ & 0.749 \\
\hline & $\mathrm{C}$ & $93.2 \pm 4.3$ & $93.1 \pm 4.2$ & 0.925 \\
\hline \multirow{4}{*}{ Fat $(\mathrm{g} / \mathrm{d})$} & JW & $69.1 \pm 3.2$ & $68 \pm 3.5$ & 0.370 \\
\hline & DS & $66.4 \pm 3$ & $66.1 \pm 4.3$ & 0.782 \\
\hline & JD & $68.2 \pm 3.2$ & $66.8 \pm 2.3$ & 0.173 \\
\hline & $\mathrm{C}$ & $68.1 \pm 3.7$ & $68 \pm 3.5$ & 0.944 \\
\hline \multirow{4}{*}{$\mathrm{CHO}(\mathrm{g} / \mathrm{d})$} & JW & $242.5 \pm 9.3$ & $241.9 \pm 7.1$ & 0.812 \\
\hline & DS & $247.6 \pm 10.2$ & $246.4 \pm 7.7$ & 0.578 \\
\hline & $\mathrm{JD}$ & $247.2 \pm 10.2$ & $247.5 \pm 10.1$ & 0.915 \\
\hline & C & $243.1 \pm 10.4$ & $242.1 \pm 7$ & 0.745 \\
\hline
\end{tabular}

Abbreviations: $\mathrm{CHO}$, carbohydrate; Kcal/d, kilocalorie/day; g/d, gram/day; JW, jump rope exercise + white chocolate supplementation; DS, dark chocolate supplementation; JD; C, control. P, $p$-value between baseline and post-intervention. Values are Mean \pm SD.

\subsection{Body Composition}

Participant's anthropometric characteristics, body composition, and inflammatory responses are presented in Table 4. All three intervention groups had significant $(p<0.05)$ decreases in body mass $(\mathrm{JW}=-1.2 \mathrm{~kg}(95 \%$ confidence interval $[\mathrm{CI}]=1.5$ to $0.9 ; \mathrm{ES}=2.2 ; p<0.001), \mathrm{DS}=-0.5 \mathrm{~kg}(95 \% \mathrm{CI}=$ -0.7 to $-0.3, \mathrm{ES}=1.5, p<0.001)$, and JD $=-2.8 \mathrm{~kg}(95 \% \mathrm{CI}=-3.1$ to $-2.4, \mathrm{ES}=5.3, p<0.001))$; $\mathrm{BMI}(\mathrm{JW}$ 
$=-0.4 \mathrm{~kg} / \mathrm{m}^{2}(95 \% \mathrm{CI}=-0.5$ to $-0.3, \mathrm{ES}=2.4, p<0.001), \mathrm{DS}=-0.2 \mathrm{~kg} / \mathrm{m}^{2}(95 \% \mathrm{CI}=-0.3$ to $-0.1, \mathrm{ES}=$ $1.2, p=0.001)$, and JD $=-1 \mathrm{~kg} / \mathrm{m}^{2}(95 \% \mathrm{CI}=-1.1$ to $\left.-0.8, \mathrm{ES}=5.5, p<0.001)\right)$; WHR [JW $=-0.006 \mathrm{~m}$ $(95 \% \mathrm{CI}=-0.01$ to $-0.002, \mathrm{ES}=1.1, p=0.005), \mathrm{DS}=-0.003 \mathrm{~m}(95 \% \mathrm{CI}=-0.006$ to $0, \mathrm{ES}=0.7, p=0.039)$ and JD $=-0.01 \mathrm{~m}(95 \% \mathrm{CI}=-0.01$ to $0.01, \mathrm{ES}=2.5, p<0.001))$; and $\mathrm{FM}(\mathrm{JW}=-0.2 \mathrm{~kg}(95 \% \mathrm{CI}=-0.4$ to $-0.1, \mathrm{ES}=0.1, p<0.001), \mathrm{DS}=-0.1 \mathrm{~kg}(95 \% \mathrm{CI}=-0.1$ to $0.09, \mathrm{ES}=2.1), p<0.001)$, and JD $=-0.6 \mathrm{~kg}$ $(95 \% \mathrm{CI}=-0.7$ to $-0.5, \mathrm{ES}=4, p<0.001))$ over time. No alterations in these variables were detected in the $\mathrm{C}$ group.

Table 4. Physiological characteristics of participants. Data are mean \pm SD.

\begin{tabular}{|c|c|c|c|c|}
\hline Variables & Group & Baseline & Post-Intervention & Mean Change \\
\hline \multirow{4}{*}{ Body mass (kg) } & JW & $87.7 \pm 5.6$ & $86.4 \pm 5.7^{*}$ & $-1.2 \pm 0.5$ \\
\hline & DS & $88 \pm 4.4$ & $87.5 \pm 4.5^{*}$ & $-0.5 \pm 0.3$ \\
\hline & JD & $89.7 \pm 5.6$ & $86.9 \pm 5.6^{*}$ & $-2.8 \pm 0.5$ \\
\hline & $\mathrm{C}$ & $90.2 \pm 5.7$ & $90.3 \pm 5.7$ & $0.02 \pm 0.2$ \\
\hline \multirow{4}{*}{ BMI $\left(\mathrm{kg} / \mathrm{m}^{2}\right)$} & JW & $32 \pm 2.2$ & $31.5 \pm 2.3 *$ & $-0.4 \pm 0.2$ \\
\hline & DS & $31.3 \pm 2.3$ & $31.1 \pm 2.2 *$ & $-0.2 \pm 0.1$ \\
\hline & JD & $32.4 \pm 2.2$ & $31.4 \pm 2.3 *$ & $-1 \pm 0.1$ \\
\hline & $\mathrm{C}$ & $33.2 \pm 2.9$ & $33.2 \pm 2.9$ & $0.02 \pm 0.1$ \\
\hline \multirow{4}{*}{ WHR (m) } & JW & $0.99 \pm 0.03$ & $0.98 \pm 0.03 *$ & $-0.006 \pm 0.006$ \\
\hline & DS & $0.98 \pm 0.04$ & $0.98 \pm 0.04 *$ & $-0.003 \pm 0.004$ \\
\hline & JD & $0.99 \pm 0.03$ & $0.97 \pm 0.03 *$ & $-0.01 \pm 0.004$ \\
\hline & $\mathrm{C}$ & $1 \pm 0.02$ & $1 \pm 0.02$ & $0.001 \pm 0.007$ \\
\hline \multirow{4}{*}{ FM (kg) } & JW & $32 \pm 1.8$ & $31.7 \pm 1.9 *$ & $-0.2 \pm 0.1$ \\
\hline & DS & $32.2 \pm 2.6$ & $32.1 \pm 2.5^{*}$ & $-0.1 \pm 0.06$ \\
\hline & $\mathrm{JD}$ & $32.8 \pm 1.8$ & $32.1 \pm 1.8^{*}$ & $-0.6 \pm 0.1$ \\
\hline & $\mathrm{C}$ & $33 \pm 1.9$ & $33.1 \pm 1.9$ & $0.02 \pm 0.08$ \\
\hline
\end{tabular}

Abbreviations: JW, jump rope + placebo; DS, dark chocolate supplementation, JD, jump rope + dark chocolate supplementation; $\mathrm{C}$, control; WHR, waist hip ratio; FM, Fat Mass. ${ }^{*} p<0.05$ different from pre-training.

\subsection{Pro-Inflammatory Cytokines}

Figure 2 depicts pro-inflammatory cytokine concentrations. All 3 intervention groups had significantly $(p<0.05)$ reduced hs-CRP (JW $=-0.1 \mathrm{ng} / \mathrm{mL}(95 \% \mathrm{CI}=-0.1$ to $-0.06, \mathrm{ES}=1.6, p<0.001)$, $\mathrm{DS}=-0.09 \mathrm{ng} / \mathrm{mL}(95 \% \mathrm{CI}=-0.1$ to $-0.06, \mathrm{ES}=2.2, p<0.001)$, and JD $=-0.3 \mathrm{ng} / \mathrm{mL}(95 \% \mathrm{CI}=-0.4$ to $-0.2, \mathrm{ES}=3.5, p<0.001))$; TNF- $\alpha(\mathrm{JW}=-4.7 \mathrm{pg} / \mathrm{mL}(95 \% \mathrm{CI}=-6.7$ to $-2.6, \mathrm{ES}=1.4, p<0.001), \mathrm{DS}$ $=-1.5 \mathrm{pg} / \mathrm{mL}(95 \% \mathrm{CI}=-3.1$ to $-0.04, \mathrm{ES}=0.6, p=0.045)$, and $\mathrm{JD}=-7.7 \mathrm{pg} / \mathrm{mL}(95 \% \mathrm{CI}=-9.3$ to $-6.1, \mathrm{ES}=3.1, p<0.001)$ ); and IL-6 (JW $=-3.4 \mathrm{pg} / \mathrm{mL}(95 \% \mathrm{CI}=-4.8$ to $-2.1, \mathrm{ES}=1.5, p<0.001)$, DS $=-2.3 \mathrm{pg} / \mathrm{mL}(95 \% \mathrm{CI}=-4.1$ to $-0.5, \mathrm{ES}=0.8, p=0.016)$, and JD $=-10.2 \mathrm{pg} / \mathrm{mL}(95 \% \mathrm{CI}=-14.5$ to $-5.9, \mathrm{ES}=1.6, p<0.001)$ ) over time. No alterations in these variables were detected in the $\mathrm{C}$ group. These decreases in the JD group was greater than other groups. There was a significant between-group difference for diminished IL-6 concentrations in JD compared to $C$ group. 
A)

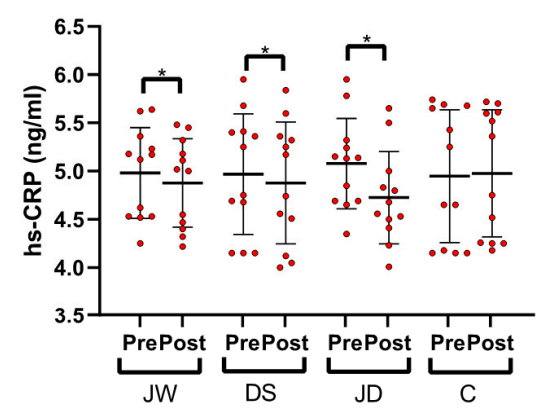

B)

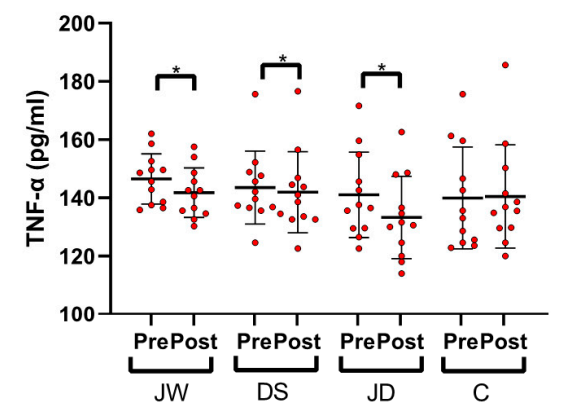

C)

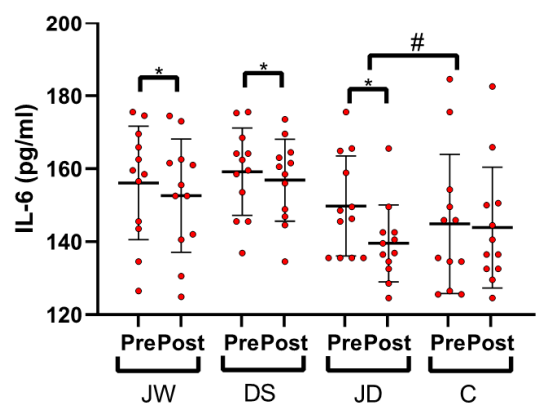

Figure 2. Pro-inflammatory cytokine concentrations. (A) high-sensitivity-reactive protein (hs-CRP), (B) tumor necrosis factor- $\alpha$ (TNF- $\alpha$ ), (C) Interleukin-6 (IL-6). ${ }^{*} p<0.05$ different from pre-training; \# between group difference.

\subsection{Pro-Inflammatory and Anti-Inflammatory Adipokines}

Adipokines concentrations are shown in Figure 3. All 3 intervention groups demonstrated significantly $(p<0.05)$ reduced leptin (JW $=-0.03 \mathrm{ng} / \mathrm{mL}(95 \% \mathrm{CI}=-0.06$ to -0.01 , $\mathrm{ES}=1, p=0.003)$, $\mathrm{DS}=-0.01 \mathrm{ng} / \mathrm{mL}(95 \% \mathrm{CI}=-0.02$ to $-0.004, \mathrm{ES}=1, p=0.008)$, and $\mathrm{JD}=-0.09 \mathrm{ng} / \mathrm{mL}(95 \% \mathrm{CI}=-0.1$ to -0.07 , $\mathrm{ES}=4.5, p<0.001)$ ); resistin (JW $=-0.05 \mathrm{ng} / \mathrm{mL}(95 \% \mathrm{CI}=-0.08$ to $-0.02, \mathrm{ES}=0.1, p=0.003)$, $\mathrm{DS}=-0.01 \mathrm{ng} / \mathrm{mL}(95 \% \mathrm{CI}=-0.02$ to $-0.002, \mathrm{ES}=1, p=0.021)$, and $\mathrm{JD}=-0.1 \mathrm{ng} / \mathrm{mL}(95 \% \mathrm{CI},-0.1$ to $-0.07, \mathrm{ES}=2.2, p<0.001)$ ); $\mathrm{MCP}-1(\mathrm{JW}=-7.8 \mathrm{pg} / \mathrm{mL}(95 \% \mathrm{CI}=-9.9$ to -5.6$), \mathrm{ES}=2.3, p<0.001), \mathrm{DS}=$ $-2.8 \mathrm{pg} / \mathrm{mL}(95 \% \mathrm{CI}=-5.5$ to $0.1, \mathrm{ES}=0.6, p=0.041)$, and JD $=-15.1 \mathrm{pg} / \mathrm{mL}(95 \% \mathrm{CI}=-17.9$ to -12.2 , $\mathrm{ES}=3.3, p<0.001)$ ); and RBP-4 (JW $=-1.9 \mathrm{~g} / \mathrm{mL}(95 \% \mathrm{CI}=-2.5$ to $-1.3, \mathrm{ES}=2.2, p<0.001)$, DS $=-1.2$ $\mathrm{ng} / \mathrm{mL}(95 \% \mathrm{CI}=-2$ to $-0.4, \mathrm{ES}=1, p=0.004)$, and JD $=-5.1 \mathrm{ng} / \mathrm{mL}(95 \% \mathrm{CI},-5.9$ to $-4.3, \mathrm{ES}=4, p<$ $0.001)$ ) over time. No alterations in these variables were detected in the $C$ group. Only Chemerin $(-4.2$ $\mathrm{ng} / \mathrm{mL}(95 \% \mathrm{CI}=-5.2$ to $-3.2, \mathrm{ES}=2.7, p<0.001))$ concentrations significantly diminished $(p<0.05)$ only in the JD group. 
A)

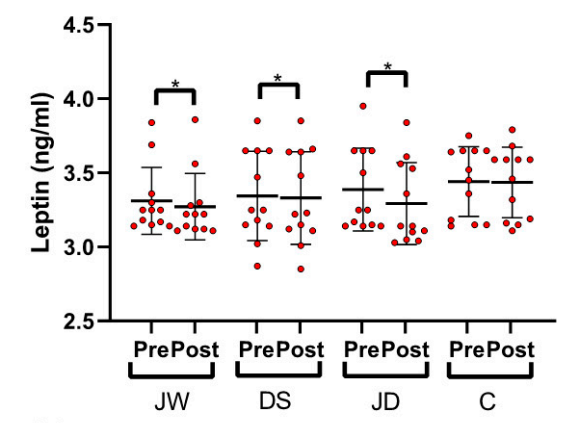

C)
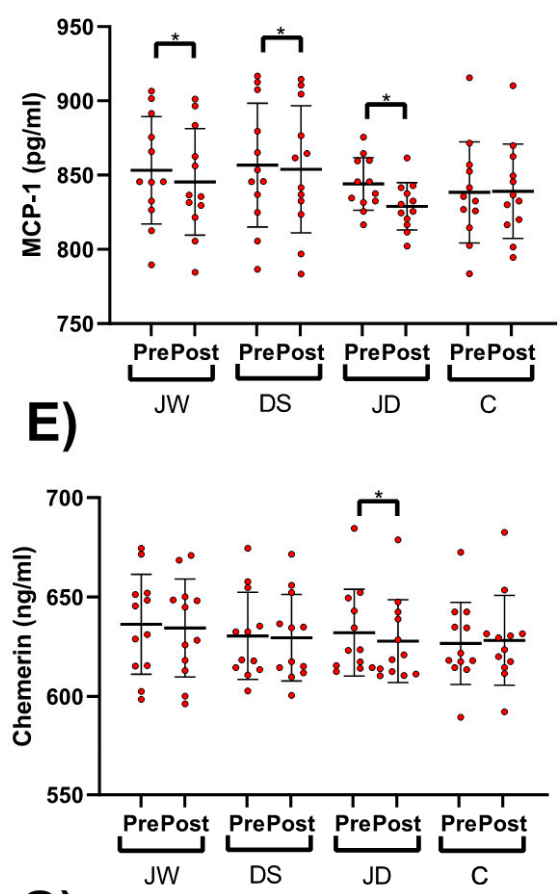

G)

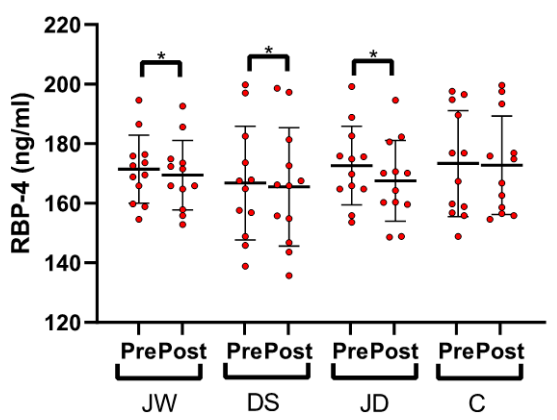

B)

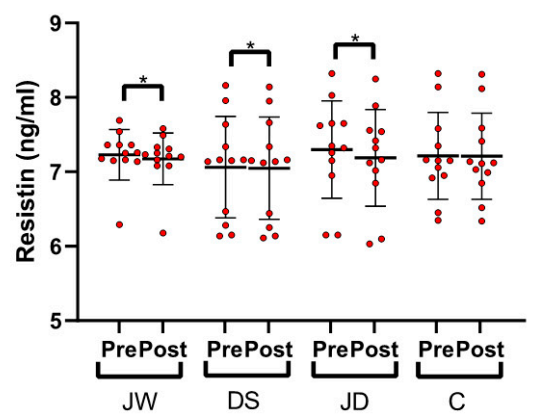

D)
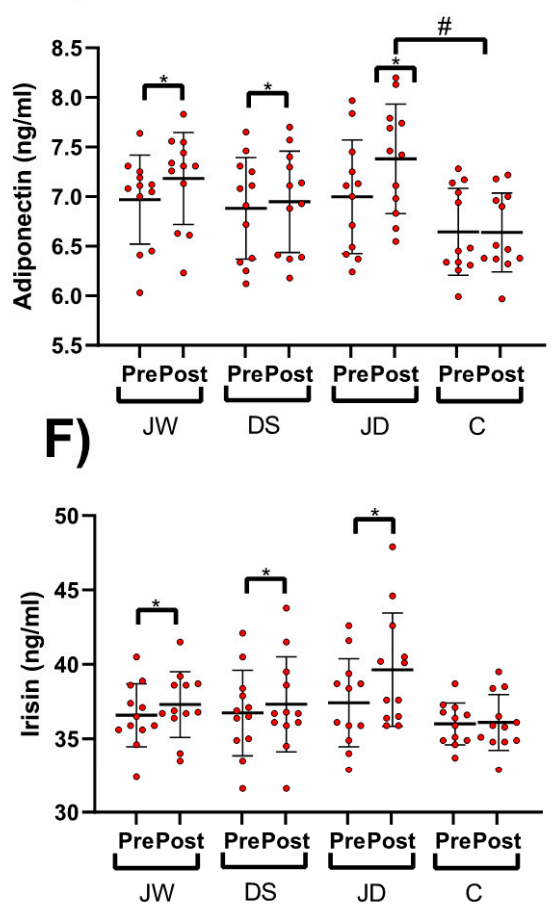

Figure 3. Pro-Inflammatory and anti-inflammatory adipokines concentrations. (A) Leptin, (B) Resistin. (C) Monocyte chemoattractant protein-1 (MCP-1), (D) Adiponectin, (E) Chemerin, (F) Irisin, (G) Retinol-binding protein-4 (RBP-4). ${ }^{*} p<0.05$ different from pre-training; \# between group difference.

Anti-inflammatory adipokine concentrations were altered in all 3 intervention groups over time whereby significant $(p<0.05)$ increases in irisin $(\mathrm{JW}=0.7 \mathrm{ng} / \mathrm{mL}(95 \% \mathrm{CI}=0.3$ to $1.1, \mathrm{ES}=1.1, p=$ $0.002), \mathrm{DS}=0.5 \mathrm{ng} / \mathrm{mL}(95 \% \mathrm{CI}=0.1$ to $1, \mathrm{ES}=0.8, p=0.012)$, and JD $=2.2 \mathrm{ng} / \mathrm{mL}(95 \% \mathrm{CI}=1.2$ to 3.2 , $\mathrm{ES}=1.4, p<0.001)$ ) and adiponectin (JW $=0.2 \mathrm{ng} / \mathrm{mL}(95 \% \mathrm{CI}=0.1$ to 0.2$), \mathrm{ES}=5, p<0.001), \mathrm{DS}=$ 
$0.06 \mathrm{ng} / \mathrm{mL}(95 \% \mathrm{CI}=0.03$ to $0.09, \mathrm{ES}=1.5, p<0.001)$, and $\mathrm{JD}=0.3 \mathrm{ng} / \mathrm{mL}(95 \% \mathrm{CI}=0.2$ to $0.4, \mathrm{ES}$ $=2.9, p<0.001)$ were observed. No changes were identified in the $\mathrm{C}$ group. There was a significant between-group difference for improved adiponectin concentrations in JD compared to $\mathrm{C}$ group.

\section{Discussion}

We aimed at evaluating the effects of JRE following dark chocolate supplementation on pro-inflammatory cytokines (hs-CRP, TNF- $\alpha$, IL-6), adipokines (leptin, resistin, RBP-4, chemerin, MCP-1), and anti-inflammatory adipokines (irisin, adiponectin) in obese adolescent boys. To the best of our knowledge, our study is the first to assess the influence of combining JRE and dark chocolate supplementation on inflammatory markers in this population. Moreover, this study provides for the novel evaluation of RBP-4, chemerin, and resistin after JRE or dark chocolate supplementation. Briefly, our three main findings were as follows: (1) All intervention groups elicited significant reductions in hs-CRP, IL-6, leptin, resistin, MCP-1, and RBP-4 as well as significant increases in irisin and adiponectin concentrations and these alterations were greater in the JD group. (2) Chemerin concentrations significantly decreased only in the JD group, while no changes were observed in all other interventions and the $C$ group. (3) Although all three interventions significantly decreased body mass, BMI, WHR, and FM, no significant between group changes were observed.

Adiponectin known as a hormone secreted mainly by adipose tissue and targets tissues such as skeletal muscle and liver. Among other functions, it controls metabolism of energy and insulin sensitivity [28,29]. It has been revealed that adiponectin concentrations increased significantly following both high- and moderate-intensity interval training in obese young females [30]. Furthermore, both animal and human studies showed possible effects of cocoa and dark chocolate supplementation on both adiponectin circulating concentrations and gene expression [31,32]. Although there is a shred of evidence on the positive influences of both exercise and dark chocolate supplementation on circulating concentrations of adiponectin, the combination of these two treatments has been insufficiently researched. Our findings underlined that JRE and dark chocolate supplementation either alone or in combination increased adiponectin concentrations, however, the JD induced rise in adiponectin concentrations was greatest compared to $C$ group. A possible mechanism of how dark chocolate supplementation and/or JRE affect adiponectin concentrations may be explained by the observed reduction in adiposity [31] and subsequent catechin-induced promotion of $\beta$-oxidation in the liver [33]. In addition, it has been shown that flavonoids in the dark chocolate act on peroxisome proliferator-activated receptors (PPARs) [34] and also serve to increase expression of peroxisome proliferator-activated receptor-gamma (PPAR- $\gamma$ ) which in turn may increase adiponectin expression [34]. It is also understood that adiponectin has an inverse association with BMI and FM [35] which as explained is influenced by physical activity levels [36,37]. Prior research demonstrated that the alterations of adiponectin concentrations were related to decrements of body fat as a result of both high- and moderate-intensity interval training [30]. Therefore, the resultant and heightened changes in adiponectin concentrations in the JD group may partially account for greater decreases in FM. Because adiponectin concentrations also increased in the JW group, it is important to note that traditional aerobic [38] and resistance exercise [39] have not altered adiponectin concentrations in obese adolescents, suggesting that JRE may have a greater influence on this important adipokine.

The main source of pro-inflammatory cytokine secretion is adipose tissue. It has been reported that both JRE and dark chocolate supplementation reduces concentrations of pro-inflammatory cytokines [7,40,41]. For instance, Sung et al. showed that 12 weeks of JRE decreased systemic inflammation by reducing hs-CRP concentrations in prehypertensive adolescent girls [7]. However, six weeks of JRE ( $40 \mathrm{~min} / \mathrm{d}, 5 \mathrm{~d} / \mathrm{wk}$ ) failed to induce any significant changes in TNF- $\alpha$, IL-6, and hs-CRP concentrations in obese male adolescents [4]. With respect to the inflammatory responses following dark chocolate or cocoa consumption, the possible effects on pro-inflammatory cytokines remain inconsistent in the literature [10]. It has been previously shown that individuals who received dark chocolate in combination with therapeutic lifestyle changes had lower concentrations of inflammatory markers such 
as hs-CRP, TNF- $\alpha$, and IL-6 compared to therapeutic lifestyle changes alone [11]. Conversely, $40 \mathrm{~g}$ of daily cocoa powder supplementation decreased the expression of Very-late Antigen-4 (VLA-4), Cluster of differentiation 40 (CD40), and Cluster of differentiation 36 (CD36) in monocytes while circulating pro-inflammatory cytokines, including IL-6 and hs-CRP concentrations, remained unchanged in patients with high risk for cardiovascular disease [42]. Such discrepancies in the literature may be due to differences in the participant characteristics, type, the dose of cocoa and/or dark chocolate, timing and duration of intervention, and inherent methodological variability in quantifying circulating concentrations of cytokines [10,43]. Nevertheless, our results indicated that a combination of JRE and dark chocolate supplementation significantly attenuates pro-inflammatory cytokines, including hs-CRP, TNF- $\alpha$, and IL- 6 concentrations, more than either intervention alone.

Adipose tissue-secreted hormones such as leptin and resistin have significant roles in the initiation and progression of many metabolic disorders such as obesity and diabetes [44]. Previous studies showed a positive association between obesity and leptin and resistin concentrations [45-48]. Moreover, both leptin and resistin may stimulate the production of pro-inflammatory cytokines such as TNF- $\alpha$ and IL-6 via NF- $\mathrm{BB}$ activation [49-51]. Therefore, decreasing leptin and resistin concentrations may be considered a therapeutic target to reduce the inflammatory state associated with obesity [44]. To the best of our knowledge, no other study has demonstrated the influences of either dark chocolate supplementation or JRE alone on the pro-inflammatory adipokine concentrations of leptin, resistin, RBP-4, MCP-1, and chemerin. Our findings illustrated that either $30 \mathrm{~g}$ of daily dark chocolate supplementation or JRE for 6 weeks in obese adolescent boys decreased leptin, resistin, RBP-4, and MCP-1 concentrations, while chemerin concentrations remained unchanged. However, when dark chocolate supplementation and JRE were combined (JD group), chemerin concentrations decreased. Further investigations are needed to assess the influences of dark chocolate and/or cocoa supplementation on pro-inflammatory adipokines. It has been suggested that cocoa supplementation could enhance advantageous anti-inflammatory properties by mediating the inhibition of the nuclear factor kappa B (NF-kB)-dependent transcription pathway and/or interacting with specific cytokines [10]. The NF-кB pathway appears to mediate low-grade inflammation that is involved in the chronic production of pro-inflammatory cytokines and adipokines seen in obesity [52]. Anti-inflammatory effects after a single dose of $40 \mathrm{~g}$ of cocoa supplementation with water or milk in healthy participants mediated by the modulation of NF-kB activation and downstream molecules in this pathway reinforce the link between cocoa supplementation and health outcomes [53]. On the other hand, exercise training has been reported to reduce pro-inflammatory adipokines [54] through reductions in visceral fat mass (via decreased adipokines release) and the production of an anti-inflammatory environment observed with bouts of exercise [55].

Chemerin is an adipokine associated with certain chronic diseases such as diabetes and cardiovascular disease [56]. Prior studies have demonstrated that physical activity may elicit a positive effect of reducing chemerin concentrations $[57,58]$. Saremi et al. demonstrated that chemerin concentrations decreased following 12 weeks of aerobic exercise [58]. However, our outcomes did not indicate any significant change in chemerin concentration with JRE alone as noted in the JW group. These differences may be due to factors including participant characteristics, type and intensity of exercise, and variations in the exercise intervention. To the best of our knowledge, no other study has demonstrated the effects of dark chocolate and/or cocoa supplementation on chemerin concentrations. Our results further indicated that six weeks of dark chocolate supplementation had no effect on chemerin concentrations in obese adolescent boys (although chemerin trended lower). However, dark chocolate supplementation in combination with JRE (JD group) resulted in significantly decreased chemerin concentrations indicating the potential and beneficial ratio of dark chocolate supplementation to JRE as utilized in this study. Further research is needed to assess the influences of dark chocolate or cocoa supplementation with and/or without exercise interventions on chemerin concentrations to clarify the underlying mechanisms of change. 
In this study, we observed reduced body mass in all three-intervention groups, with the greatest reduction seen in JD participants. Our observation is consistent with prior research reporting declines in body mass after JRE in adolescent populations with [4,8], and without [7] obesity. Thus, our findings re-emphasize the notion that JRE is an effective intervention for improving body mass. A meta-analysis of 35 randomized control trial studies found that body mass and BMI were reduced following $30 \mathrm{~g}$ or higher of cocoa/dark chocolate supplementation per day ingested over 4-8 weeks [59] which is consistent with our findings in the DS participants. Animal studies utilizing cocoa supplementation have shed light on potential mechanisms of reduced body mass through decreased gene expression involved in liver fatty acids synthesis [60], upregulation of uncoupling proteins [61], and inhibition of insulin receptor kinase activity in adipose tissue [61]. Moreover, human dark chocolate supplementation research has shown a decrease in appetite and an increase in satiety $[62,63]$ potentially resulting from the high-fat content of chocolate, which increases gastrointestinal transit time and may raise the concentrations of satiety controlling hormones [64]. In participants supplementing dark chocolate while undertaking JRE in the present study, there appears a summative body mass-reducing effect $(-2.8 \mathrm{~kg})$ which may in part be explained by the heightened FM loss in these participants. Nevertheless, there are certain limitations in drawing such a conclusion since FM, as analyzed by the frequently utilized multi-frequency bioelectrical impedance, assumes that body hydration is normalized, constant, and unaffected by overweightness/obesity and other factors [65]. For example, it is understood that body composition is altered with overweightness/obesity, fluid shifts occur during exercise, and fluid intake influences the redistribution of body fluids [66], all of which may influence estimations of FM. These constraints, when considered in our study, may have underestimated FM in participants as similarly noted in prior research [65,67]. Finally, our JRE protocol was safe, practical, and similar to prior investigation in obese adolescents [4], yet we did not monitor exercise intensity using established methods such as the rating of perceived exertion or the percentage of heart rate or heart rate reserve; however, the American College of Sports Medicine does not indicate such monitoring as part of their current exercise recommendations for children and adolescents [68].

There are some limitations to the present research. We have not utilized the gold standard technique (Dual-energy X-ray absorptiometry (DEXA)) to evaluate body composition. However, previous studies have shown that bioelectrical impedance it is a valid and reliable method $[69,70]$. The short duration of our intervention is another limitation. Although the total caloric values of the dark and white chocolate supplementations were somewhat similar, macronutrient composition was not evenly matched; which could have, at least to a certain extent, impacted our results. Moreover, the addition of a white chocolate (placebo) supplementation combined with no exercise group would have strengthened the design of our investigation. However, it could be argued that the inclusion of such a group would result in an elevated risk of "non-treatment" as a control group is already present our study. Addressing these four limitations warrants further studies with a larger population and longer duration.

\section{Conclusions}

This study demonstrated that dark chocolate supplementation potentiated JRE-induced decreases in body mass, WHR, FM, hs-CRP, TNF- $\alpha$, IL-6, leptin, resistin, RBP-4, and MCP-1, as well as increases irisin and adiponectin concentrations. JRE by itself was unable to alter serum concentrations of chemerin, however, when combined with dark chocolate, chemerin concentrations decreased in obese adolescent boys. Based on our results, the combination of JRE with dark chocolate supplementation could be a beneficial strategy to moderate obesity-induced inflammation in adolescent boys. Further longer-term studies are needed to confirm our results.

Author Contributions: M.E., E.E., and B.H.M. conceived and designed research. B.H.M., E.E., and M.E. conducted experiments. R.B. contributed new reagents or analytical tools. A.W. and R.B. analyzed data. R.B. and D.A.-L. wrote the manuscript. A.W., R.B., D.A.-L., M.N., and F.D. revised the manuscript. All authors have read and agreed to the published version of the manuscript. 
Funding: This study was supported by Department of Exercise Physiology, University of Tehran, Tehran, Iran. (Grant number: 1397).

Acknowledgments: The authors wish to thank all the participants in this research project.

Conflicts of Interest: The authors declare no conflict of interest.

\section{References}

1. Swinburn, B.A.; Sacks, G.; Hall, K.D.; McPherson, K.; Finegood, D.T.; Moodie, M.L.; Gortmaker, S.L. The global obesity pandemic: Shaped by global drivers and local environments. Lancet 2011, 378, 804-814. [CrossRef]

2. Chorin, E.; Hassidim, A.; Hartal, M.; Havakuk, O.; Flint, N.; Ziv-Baran, T.; Arbel, Y. Trends in adolescents obesity and the association between BMI and blood pressure: A cross-sectional study in 714,922 healthy teenagers. Am. J. Hypertens. 2015, 28, 1157-1163. [CrossRef] [PubMed]

3. Nunes, P.R.; Martins, F.M.; Souza, A.P.; Carneiro, M.A.; Orsatti, C.L.; Michelin, M.A.; Murta, E.F.; de Oliveira, E.P.; Orsatti, F.L. Effect of high-intensity interval training on body composition and inflammatory markers in obese postmenopausal women: A randomized controlled trial. Menopause 2019, 26, 256-264. [CrossRef] [PubMed]

4. Kim, E.S.; Im, J.A.; Kim, K.C.; Park, J.H.; Suh, S.H.; Kang, E.S.; Kim, S.H.; Jekal, Y.; Lee, C.W.; Yoon, Y.J. Improved insulin sensitivity and adiponectin level after exercise training in obese Korean youth. Obesity 2007, 15, 3023-3030. [CrossRef]

5. Tomeleri, C.M.; Ribeiro, A.S.; Souza, M.F.; Schiavoni, D.; Schoenfeld, B.J.; Venturini, D.; Barbosa, D.S.; Landucci, K.; Sardinha, L.B.; Cyrino, E.S. Resistance training improves inflammatory level, lipid and glycemic profiles in obese older women: A randomized controlled trial. Exp. Gerontol. 2016, 84, 80-87. [CrossRef]

6. Mohamadzadeh Salamat, K.; Bakhtiari, N. The Effects of Endurance and Resistance Training on Systemic Inflammatory Markers and Metabolic Syndrome Parameters in Overweight and Obese Men. Rep. Health Care 2017, 3, 15-26.

7. Sung, K.-D.; Pekas, E.J.; Scott, S.D.; Son, W.-M.; Park, S.-Y. The effects of a 12-week jump rope exercise program on abdominal adiposity, vasoactive substances, inflammation, and vascular function in adolescent girls with prehypertension. Eur. J. Appl. Physiol. 2019, 119, 577-585. [CrossRef]

8. Kim, J.; Son, W.-M.; Headid, R.J., III; Pekas, E.J.; Noble, J.M.; Park, S.-Y. The effects of a 12-week jump rope exercise program on body composition, insulin sensitivity, and academic self-efficacy in obese adolescent girls. J. Pediatr. Endocrinol. Metab. 2020, 33, 129-137. [CrossRef]

9. Loayza, D.; De Lange, T. POT1 as a terminal transducer of TRF1 telomere length control. Nature 2003, 423, 1013-1018. [CrossRef]

10. Khan, N.; Khymenets, O.; Urpí-Sardà, M.; Tulipani, S.; Garcia-Aloy, M.; Monagas, M.; Mora-Cubillos, X.; Llorach, R.; Andres-Lacueva, C. Cocoa polyphenols and inflammatory markers of cardiovascular disease. Nutrients 2014, 6, 844-880. [CrossRef]

11. Jafarirad, S.; Ayoobi, N.; Karandish, M.; Jalali, M.-T.; Haghighizadeh, M.H.; Jahanshahi, A. Dark chocolate effect on serum adiponectin, biochemical and inflammatory parameters in diabetic patients: A randomized clinical trial. Int. J. Prev. Med. 2018, 9, 86. [CrossRef] [PubMed]

12. Haghighat, N.; Rostami, A.; Eghtesadi, S.; Shidfar, F.; Heidari, I.; Hoseini, A. The effects of dark chocolate on lipid profile, apo-lipoprotein A-1, apo-lipoprotein B and inflammation in type-2 diabetic patients: A randomized clinical trial. Iran. J. Nutr. Sci. Food Technol. 2013, 8, 21-30.

13. Ellinger, S.; Stehle, P. Impact of cocoa consumption on inflammation processes-A critical review of randomized controlled trials. Nutrients 2016, 8, 321. [CrossRef] [PubMed]

14. You, T.; Arsenis, N.C.; Disanzo, B.L.; LaMonte, M.J. Effects of exercise training on chronic inflammation in obesity. Sports Med. 2013, 43, 243-256. [CrossRef] [PubMed]

15. Paltoglou, G.; Schoina, M.; Valsamakis, G.; Salakos, N.; Avloniti, A.; Chatzinikolaou, A.; Margeli, A.; Skevaki, C.; Papagianni, M.; Kanaka-Gantenbein, C. Interrelations among the adipocytokines leptin and adiponectin, oxidative stress and aseptic inflammation markers in pre-and early-pubertal normal-weight and obese boys. Endocrine 2017, 55, 925-933. [CrossRef] 
16. Sirico, F.; Bianco, A.; D’Alicandro, G.; Castaldo, C.; Montagnani, S.; Spera, R.; Di Meglio, F.; Nurzynska, D. Effects of physical exercise on adiponectin, leptin, and inflammatory markers in childhood obesity: Systematic review and meta-analysis. Child. Obes. 2018, 14, 207-217. [CrossRef]

17. Izadpanah, A.; Barnard, R.J.; Almeda, A.J.E.; Baldwin, G.C.; Bridges, S.A.; Shellman, E.R.; Burant, C.F.; Roberts, C.K. A short-term diet and exercise intervention ameliorates inflammation and markers of metabolic health in overweight/obese children. Am. J. Physiol. Endocrinol. Metab. 2012, 303, E542-E550. [CrossRef]

18. Blüher, S.; Panagiotou, G.; Petroff, D.; Markert, J.; Wagner, A.; Klemm, T.; Filippaios, A.; Keller, A.; Mantzoros, C.S. Effects of a 1-year exercise and lifestyle intervention on irisin, adipokines, and inflammatory markers in obese children. Obesity 2014, 22, 1701-1708. [CrossRef]

19. Rosner, B.; Prineas, R.; Loggie, J.; Daniels, S.R. Percentiles for body mass index in US children 5 to 17 years of age. J. Pediatr. 1998, 132, 211-222. [CrossRef]

20. Ashtary-Larky, D.; Daneghian, S.; Alipour, M.; Rafiei, H.; Ghanavati, M.; Mohammadpour, R.; Kooti, W.; Ashtary-Larky, P.; Afrisham, R. Waist circumference to height ratio: Better correlation with fat mass than other anthropometric indices during dietary weight loss in different rates. Int. J. Endocrinol. Metab. 2018, 16, e55023. [CrossRef]

21. Patel, R.K.; Brouner, J.; Spendiff, O. Dark chocolate supplementation reduces the oxygen cost of moderate intensity cycling. J. Int. Soc. Sports Nutr. 2015, 12, 47. [CrossRef] [PubMed]

22. Martin, F.-P.J.; Rezzi, S.; Peré-Trepat, E.; Kamlage, B.; Collino, S.; Leibold, E.; Kastler, J.; Rein, D.; Fay, L.B.; Kochhar, S. Metabolic effects of dark chocolate consumption on energy, gut microbiota, and stress-related metabolism in free-living subjects. J. Proteome Res. 2009, 8, 5568-5579. [CrossRef] [PubMed]

23. Rezazadeh, A.; Mahmoodi, M.; Mard, S.A.; karimi Moghaddam, E. The effects of dark chocolate consumption on lipid profile, fasting blood sugar, liver enzymes, inflammation, and antioxidant status in patients with non-alcoholic fatty liver disease: A randomized, placebo-controlled, pilot study. J. Gastroenterol. Hepatol. Res. 2015, 4, 1858-1864.

24. Ashtary-Larky, D.; Kheirollah, A.; Bagheri, R.; Ghaffari, M.A.; Mard, S.A.; Hashemi, S.J.; Mir, I.; Wong, A. A single injection of vitamin D 3 improves insulin sensitivity and $\beta$-cell function but not muscle damage or the inflammatory and cardiovascular responses to an acute bout of resistance exercise in vitamin D-deficient resistance-trained males. Br. J. Nutr. 2020, 123, 394-401. [CrossRef]

25. Bagheri, R.; Rashidlamir, A.; Ashtary-Larky, D.; Wong, A.; Alipour, M.; Motevalli, M.S.; Chebbi, A.; Laher, I.; Zouhal, H. Does Green Tea Extract Enhance the Anti-inflammatory Effects of Exercise on Fat Loss? Br. J. Clin. Pharmacol. 2019. [CrossRef]

26. Faul, F.; Erdfelder, E.; Lang, A.-G.; Buchner, A. G*Power 3: A flexible statistical power analysis program for the social, behavioral, and biomedical sciences. Behav. Res. Methods 2007, 39, 175-191. [CrossRef]

27. Cohen, J. A power primer. Psychol. Bull. 1992, 112, 155-159. [CrossRef]

28. Lafontan, M.; Viguerie, N. Role of adipokines in the control of energy metabolism: Focus on adiponectin. Curr. Opin. Pharmacol. 2006, 6, 580-585. [CrossRef]

29. Shirali, S.; Daneghian, S.; Hosseini, S.A.; Ashtary-Larky, D.; Daneghian, M.; Mirlohi, M.-S. Effect of caffeine co-ingested with carnitine on weight, body-fat percent, serum leptin and lipid profile changes in male teen soccer players: A randomized clinical trial. Int. J. Pediatr. 2016, 4, 3685-3698.

30. Racil, G.; Ounis, O.B.; Hammouda, O.; Kallel, A.; Zouhal, H.; Chamari, K.; Amri, M. Effects of high vs. moderate exercise intensity during interval training on lipids and adiponectin levels in obese young females. Eur. J. Appl. Physiol. 2013, 113, 2531-2540. [CrossRef]

31. Ali, F.; Ismail, A.; Kersten, S. Molecular mechanisms underlying the potential antiobesity-related diseases effect of cocoa polyphenols. Mol. Nutr. Food Res. 2014, 58, 33-48. [CrossRef] [PubMed]

32. Gu, Y.; Yu, S.; Lambert, J.D. Dietary cocoa ameliorates obesity-related inflammation in high fat-fed mice. Eur. J. Nutr. 2014, 53, 149-158. [CrossRef] [PubMed]

33. Murase, T.; Nagasawa, A.; Suzuki, J.; Hase, T.; Tokimitsu, I. Beneficial effects of tea catechins on diet-induced obesity: Stimulation of lipid catabolism in the liver. Int. J. Obes. 2002, 26, 1459-1464. [CrossRef] [PubMed]

34. Magrone, T.; Russo, M.A.; Jirillo, E. Cocoa and dark chocolate polyphenols: From biology to clinical applications. Front. Immunol. 2017, 8, 677. [CrossRef] [PubMed]

35. Lubkowska, A.; Radecka, A.; Bryczkowska, I.; Rotter, I.; Laszczyńska, M.; Dudzińska, W. Serum adiponectin and leptin concentrations in relation to body fat distribution, hematological indices and lipid profile in humans. Int. J. Environ. Res. Public Health 2015, 12, 11528-11548. [CrossRef] 
36. Tsukinoki, R.; Morimoto, K.; Nakayama, K. Association between lifestyle factors and plasma adiponectin levels in Japanese men. Lipids Health Dis. 2005, 4, 27. [CrossRef]

37. Simpson, K.A.; Singh, M.A.F. Effects of exercise on adiponectin: A systematic review. Obesity 2008, 16, 241-256. [CrossRef]

38. Nassis, G.P.; Papantakou, K.; Skenderi, K.; Triandafillopoulou, M.; Kavouras, S.A.; Yannakoulia, M.; Chrousos, G.P.; Sidossis, L.S. Aerobic exercise training improves insulin sensitivity without changes in body weight, body fat, adiponectin, and inflammatory markers in overweight and obese girls. Metabolism 2005, 54, 1472-1479. [CrossRef]

39. Ahmadizad, S.; Ghorbani, S.; Ghasemikaram, M.; Bahmanzadeh, M. Effects of short-term nonperiodized, linear periodized and daily undulating periodized resistance training on plasma adiponectin, leptin and insulin resistance. Clin. Biochem. 2014, 47, 417-422. [CrossRef]

40. Zakavi, I.; Bizhani, B.; Ghaisii, M.B.H.E. The Effect of an Eight-Week Rope Skipping Exercise Program on Interleukin-10 and C-Reactive Protein in Overweight and Obese Adolescents. Jentashapir J. Health Res. 2015, 6. [CrossRef]

41. Kuebler, U.; Arpagaus, A.; Meister, R.E.; von Känel, R.; Huber, S.; Ehlert, U.; Wirtz, P.H. Dark chocolate attenuates intracellular pro-inflammatory reactivity to acute psychosocial stress in men: A randomized controlled trial. Brain Behav. Immun. 2016, 57, 200-208. [CrossRef] [PubMed]

42. Monagas, M.; Khan, N.; Andres-Lacueva, C.; Casas, R.; Urpi-Sarda, M.; Llorach, R.; Lamuela-Raventos, R.M.; Estruch, R. Effect of cocoa powder on the modulation of inflammatory biomarkers in patients at high risk of cardiovascular disease. Am. J. Clin. Nutr. 2009, 90, 1144-1150. [CrossRef] [PubMed]

43. Ghafourian, M.; Ashtary-Larky, D.; Chinipardaz, R.; Eskandary, N.; Mehavaran, M. Inflammatory biomarkers' response to two different intensities of a single bout exercise among soccer players. Iran. Red Crescent Med. J. 2016, 18, e21498. [CrossRef] [PubMed]

44. Al-Suhaimi, E.A.; Shehzad, A. Leptin, resistin and visfatin: The missing link between endocrine metabolic disorders and immunity. Eur. J. Med. Res. 2013, 18, 12. [CrossRef] [PubMed]

45. Liuzzi, A.; Savia, G.; Tagliaferri, M.; Lucantoni, R.; Berselli, M.; Petroni, M.; De Medici, C.; Viberti, G. Serum leptin concentration in moderate and severe obesity: Relationship with clinical, anthropometric and metabolic factors. Int. J. Obes. 1999, 23, 1066-1073. [CrossRef]

46. Al Maskari, M.Y.; Alnaqdy, A.A. Correlation between serum leptin levels, body mass index and obesity in Omanis. Sultan Qaboos Univ. Med. J. 2006, 6, 27-31. [PubMed]

47. Degawa-Yamauchi, M.; Bovenkerk, J.E.; Juliar, B.E.; Watson, W.; Kerr, K.; Jones, R.; Zhu, Q.; Considine, R.V. Serum resistin (FIZZ3) protein is increased in obese humans. J. Clin. Endocrinol. Metab. 2003, 88, 5452-5455. [CrossRef]

48. Heilbronn, L.; Rood, J.; Janderova, L.; Albu, J.; Kelley, D.; Ravussin, E.; Smith, S. Relationship between serum resistin concentrations and insulin resistance in nonobese, obese, and obese diabetic subjects. J. Clin. Endocrinol. Metab. 2004, 89, 1844-1848. [CrossRef]

49. Jiang, C.; Wang, W.; Tang, J.; Yuan, Z. The adipocytokine resistin stimulates the production of proinflammatory cytokines TNF- $\alpha$ and IL-6 in pancreatic acinar cells via NF-kB activation. J. Endocrinol. Investig. 2013, 36, 986-992.

50. Stofkova, A. Resistin and visfatin: Regulators of insulin sensitivity, inflammation and immunity. Endocr. Regul. 2010, 44, 25-36. [CrossRef]

51. Sennello, J.A.; Fayad, R.; Morris, A.M.; Eckel, R.H.; Asilmaz, E.; Montez, J.; Friedman, J.M.; Dinarello, C.A.; Fantuzzi, G. Regulation of T cell-mediated hepatic inflammation by adiponectin and leptin. Endocrinology 2005, 146, 2157-2164. [CrossRef] [PubMed]

52. Baker, R.G.; Hayden, M.S.; Ghosh, S. NF-кB, inflammation, and metabolic disease. Cell Metab. 2011, 13, 11-22. [CrossRef] [PubMed]

53. Vázquez-Agell, M.; Urpi-Sarda, M.; Sacanella, E.; Camino-López, S.; Chiva-Blanch, G.; Llorente-Cortés, V.; Tobias, E.; Roura, E.; Andres-Lacueva, C.; Lamuela-Raventos, R. Cocoa consumption reduces NF-kB activation in peripheral blood mononuclear cells in humans. Nutr. Metab. Cardiovasc. Dis. 2013, 23, 257-263. [CrossRef] [PubMed]

54. Görgens, S.W.; Eckardt, K.; Jensen, J.; Drevon, C.A.; Eckel, J. Exercise and Regulation of Adipokine and Myokine Production. In Progress in Molecular Biology and Translational Science; Elsevier: Amsterdam, The Netherlands, 2015; Volume 135, pp. 313-336. 
55. Gleeson, M.; Bishop, N.C.; Stensel, D.J.; Lindley, M.R.; Mastana, S.S.; Nimmo, M.A. The anti-inflammatory effects of exercise: Mechanisms and implications for the prevention and treatment of disease. Nat. Rev. Immunol. 2011, 11, 607-615. [CrossRef] [PubMed]

56. Hosseini, S.A.; Ghaedi, E.; Zakerkish, M.; Ghadiri, A.; Ashtary-larky, D.; Safari, M.; Parsanahad, M.; Alipour, M. Effects of ginseng extract on chemerin, apelin and glycemic biomarkers in type 2 diabetic patients. Indian J. Physiol. Pharm. 2017, 61, 152-158.

57. Neuparth, M.J.; Proença, J.B.; Santos-Silva, A.; Coimbra, S. The positive effect of moderate walking exercise on chemerin levels in Portuguese patients with type 2 diabetes mellitus. J. Investig. Med. 2014, 62, 350-353. [CrossRef]

58. Saremi, A.; Shavandi, N.; Parastesh, M.; Daneshmand, H. Twelve-Week aerobic training decreases chemerin level and improves cardiometabolic risk factors in overweight and obese men. Asian J. Sports Med. 2010, 1, 151-158. [CrossRef]

59. Kord-Varkaneh, H.; Ghaedi, E.; Nazary-Vanani, A.; Mohammadi, H.; Shab-Bidar, S. Does cocoa/dark chocolate supplementation have favorable effect on body weight, body mass index and waist circumference? A systematic review, meta-analysis and dose-response of randomized clinical trials. Crit. Rev. Food Sci. Nutr. 2018, 59, 2349-2362. [CrossRef]

60. Matsui, N.; Ito, R.; Nishimura, E.; Yoshikawa, M.; Kato, M.; Kamei, M.; Shibata, H.; Matsumoto, I.; Abe, K.; Hashizume, S. Ingested cocoa can prevent high-fat diet-induced obesity by regulating the expression of genes for fatty acid metabolism. Nutrition 2005, 21, 594-601. [CrossRef]

61. Min, S.; Yang, H.; Seo, S.; Shin, S.; Chung, M.; Kim, J.; Lee, S.; Lee, H.; Lee, K. Cocoa polyphenols suppress adipogenesis in vitro and obesity in vivo by targeting insulin receptor. Int. J. Obes. 2013, 37, 584-592. [CrossRef]

62. Massolt, E.T.; van Haard, P.M.; Rehfeld, J.F.; Posthuma, E.F.; van der Veer, E.; Schweitzer, D.H. Appetite suppression through smelling of dark chocolate correlates with changes in ghrelin in young women. Regul. Pept. 2010, 161, 81-86. [CrossRef] [PubMed]

63. Sørensen, L.B.; Astrup, A. Eating dark and milk chocolate: A randomized crossover study of effects on appetite and energy intake. Nutr. Diabetes 2011, 1, e21. [CrossRef] [PubMed]

64. Farhat, G.; Drummond, S.; Fyfe, L.; Al-Dujaili, E.A. Dark chocolate: An obesity paradox or a culprit for weight gain? Phytother. Res. 2014, 28, 791-797. [CrossRef] [PubMed]

65. Dehghan, M.; Merchant, A.T. Is bioelectrical impedance accurate for use in large epidemiological studies? Nutr. J. 2008, 7, 26. [CrossRef]

66. O'brien, C.; Young, A.; Sawka, M. Bioelectrical impedance to estimate changes in hydration status. Int. J. Sports Med. 2002, 23, 361-366. [CrossRef]

67. Deurenberg, P. Limitations of the bioelectrical impedance method for the assessment of body fat in severe obesity. Am. J. Clin. Nutr. 1996, 64, 449S-452S. [CrossRef]

68. Medicine, A.C.o.S. ACSM's Guidelines for Exercise Testing and Prescription; Lippincott Williams \& Wilkins: Philadelphia, PA, USA, 2013.

69. Ling, C.H.; de Craen, A.J.; Slagboom, P.E.; Gunn, D.A.; Stokkel, M.P.; Westendorp, R.G.; Maier, A.B. Accuracy of direct segmental multi-frequency bioimpedance analysis in the assessment of total body and segmental body composition in middle-aged adult population. Clin. Nutr. 2011, 30, 610-615. [CrossRef]

70. Jackson, A.; Pollock, M.L.; Graves, J.E.; Mahar, M. Reliability and validity of bioelectrical impedance in determining body composition. J. Appl. Physiol. 1988, 64, 529-534. [CrossRef]

(C) 2020 by the authors. Licensee MDPI, Basel, Switzerland. This article is an open access article distributed under the terms and conditions of the Creative Commons Attribution (CC BY) license (http://creativecommons.org/licenses/by/4.0/). 